\title{
Diabetic Microangiopathy in Patients with Pancreatitic Diabetes Mellitus
}

\author{
C. A. Verdonk, P.J. Palumbo, H. Gharib and L. G. Bartholomew \\ Mayo Clinic and Mayo Foundation, Rochester, Minnesota, USA
}

Received: January 15, 1975, and in revised form: May 26, 1975

\begin{abstract}
Summary. Clinically evident diabetic microangiopathy (retinopathy and nephropathy) occurred in $18 \%$ of diabetic patients with acute pancreatitis and $14 \%$ of diabetic patients with chronic pancreatitis. The presence of diabetic retinopathy and nephropathy in patients with pancreatitic diabetes without a family history of diabetes mellitus suggests that these patients have "primary" diabetes mellitus unmasked by the pancreatitis. The occurrence of diabetic microangiopathy is significantly correlated with the duration of diabetes. The frequency of these diabetic complications seems to increase when there is a family history of diabetes in patients whose pancreatitis is simultaneous with or precedes the
\end{abstract}

onset of diabetes. The majority of patients with diabetic microangiopathy were on insulin therapy, but the need for insulin treatment is an indication of the severity of the diabetes, rather than the insulin being a causative factor of the microangiopathy. The degree of steatorrhea in diabetic patients with chronic pancreatitis did not protect against the development of microangiopathy.

Key words: Diabetes mellitus, acute pancreatitis, chronic pancreatitis, diabetic retinopathy, diabetic nephropathy, diabetic microangiopathy, malabsorption, steatorrhea.
A variable percentage of patients ( 2 to $18 \%$ ) with acute pancreatitis $[7,10,14]$ and of patients $(25$ to $48 \%$ ) with chronic pancreatitis $[2,9,15]$ may develop diabetes mellitus subsequently, with manifestations ranging from abnormal glucose tolerance to fasting hyperglycemia with or without symptoms. The frequency of this association of diabetes and pancreatitis is greater than the expected occurrence of abnormal glucose tolerance tests in a random population $[1,14]$.

Diabetic retinopathy and glomerulosclerosis (diabetic microangiopathy) have been described in the diabetes associated with chronic pancreatitis $[4,5,8$, $15,16]$, but the frequency is less than the frequency in primary or genetic diabetes in patients matched for age, sex, and duration of diabetes [15]. Joffe and co-workers [6] attributed this lower frequency to the lower lipid levels in patients with pancreatitic diabetes, compared to normal controls and to patients with "primary" or "genetic" diabetes. Creutzfeldt and Perings [3] suggested that the difference in frequency of microangiopathy in patients with primary and secondary diabetes may be related to malabsorption and nutritional factors.

Whether retinopathy or nodular glomerulosclerosis represents underlying genetic diabetes in patients with pancreatitis or is related to the duration of the metabolic defect of diabetes mellitus, regardless of cause, remains a moot point. We have tried to use the data in our records to obtain more information on this problem.

\section{Material and Methods}

The records of 168 patients (Table 1) seen between Jan. 1, 1960, and Dec. 31, 1970, with the diagnoses of pancreatitis and diabetes mellitus were reviewed to collect the following data: age and sex distribution; classification of the pancreatitis (as acute or chronic, by the criteria of Sarles [13]); associated disorders of chronic alcoholism and cholelithiasis; duration of pancreatitis and of diabetes; onset of diabetes in relation to onset of pancreatitis; history of diabetes in relatives; treatment program; serum lipid levels; quantitative stool fat excretion; and presence, clinically, of diabetic microangiopathy (retinopathy and nephropathy). Acute pancreatitis and acute relapsing pancreatitis were classified as acute pancreatitis; chronic pancreatitis and chronic relapsing pancreatitis were classified as chronic pancreatitis.

Table 1. Classification of 168 Patients with Pancreatitis and Diabetes Mellitus

\begin{tabular}{lllll}
\hline & \multicolumn{2}{c}{ Pancreatitis } & & \multicolumn{2}{l}{ Family history } \\
\cline { 5 - 5 } & & & \\
Sex & Acute & Chronic & Positive & Negative \\
\hline $\mathrm{M}=129(77 \%)$ & 22 & 146 & & \\
$\mathrm{~F}=39(23 \%)$ & $(17 \mathrm{M} ; 5 \mathrm{~F})$ & $(112 \mathrm{M} ; 34 \mathrm{~F})$ & $63^{\mathrm{a}}(37 \%)$ & $105(63 \%)$ \\
\hline
\end{tabular}

a Primary relatives, 47; other relatives, 16 . 
The 22 patients with acute pancreatitis had a history of acute symptoms and had increased serum or urinary amylase values (or both) or had evidence of acute pancreatitis on abdominal exploration, with or without pancreatic biopsy. There was no evidence of pancreatic insufficiency subsequent to the bout or bouts of acute pancreatitis.

The 146 patients with chronic pancreatitis were identified by one or more of the following: (1) pancreatic calcification; (2) abdominal exploration with or without pancreatic biopsy; and (3) steatorrhea.

The diagnosis of diabetes mellitus was established by the presence of fasting hyperglycemia on two successive occasions in 156 patients and by glucose tolerance tests in 12 patients.

The year of onset of pancreatitis was defined by the date on which the diagnosis was made by the criteria listed. Likewise, the year of onset of diabetes mellitus was defined by the date on which the diagnosis of diabetes mellitus was made.

\section{Results}

There was a family history of diabetes in 63 patients $(37 \%)$ (Table 1); in 47 of these cases, first degree relatives (parents, siblings, or children) were involved.
Diabetic retinopathy, glomerulosclerosis, and necrobiosis lipoidica diabeticorum, alone or in combination, were present in 24 patients (14\%) and 10 of these had a family history of diabetes (Table 2). The onset of the diabetes was simultaneous with or subsequent to the onset of the pancreatitis in 118 patients $(70 \%) ; 42$ of these patients $(36 \%)$ had a family history of diabetes and $12 \%$ of these developed diabetic microangiopathy. A lower incidence of diabetic microangiopathy was seen in the remaining 76 patients without a family history of diabetes mellitus.

In those patients in whom the diabetes preceded the pancreatitis, diabetic microangiopathy occurred with almost equal frequency in patients with and without a family history of diabetes.

Among the patients with diabetic microangiopathy, the duration of the diabetes was not significantly different between the patients with and without a family history of diabetes. The percentage of patients with diabetic microangiopathy increased steadily with the duration of diabetes mellitus (Table 3); half of the patients with diabetes for 13 or more years had microangiopathy.

The clinical data on the 22 patients with acute pancreatitis and diabetes are shown in Table 4 . Of the eight patients $(36 \%)$ with a family history of diabetes, one-fourth had clinically evident retinopathy or nephropathy. The mean ages at onset of pancreatitis

Table 2. Diabetic Microangiopathy: Retinopathy, Nephropathy, and Necrobiosis Lipoidica Diabeticorum (24 Patients; $14 \%$ of Series)

\begin{tabular}{lll}
\hline & Family history of diabetes \\
\cline { 2 - 3 } & Positive & Negative \\
\hline $\begin{array}{l}\text { Diabetes simultaneous with or after } \\
\text { pancreatitis (118 patients; } 70 \%)\end{array}$ & & \\
Duration of diabetes (yr) & $\mathrm{N}=42$ & $\mathrm{~N}=76$ \\
$\quad$ Mean (range) & $11(0-27)$ & $6(0-23)$ \\
Complications: retinopathy & $5(12 \%)$ & $5(7 \%)$ \\
Diabetes for 10 yr or more & 12 & 14 \\
$\quad$ Retinopathy & 3 & 4 \\
Diabetes before pancreatitis & & $\mathrm{N}=29$ \\
(50 patients; 30\%) & $\mathrm{N}=21$ & $13(3-36)$ \\
Duration of diabetes (yr) & & $9(31 \%)$ \\
$\quad$ Mean (range) & $10(3-21)$ & 7 \\
Complications & $5(24 \%)$ & 1 \\
$\quad$ Retinopathy & 3 & 1 \\
$\quad$ Retinopathy \& nephropathy & 2 & 15 \\
$\quad$ Necrobiosis lipoidica diabeticorum & 0 & 5 \\
Diabetes for 10 yr or more & 9 & 1 \\
Retinopathy & 2 & 1 \\
Retinopathy \& nephropathy & 2 & 0 \\
Necrobiosis lipoidica diabeticorum & 0 & \\
\hline
\end{tabular}


Table 3. Duration of Diabetes and Occurrence of Diabetic Microangiopathy ${ }^{a}$

\begin{tabular}{llc}
\hline $\begin{array}{l}\text { Duration } \\
\text { (yr) }\end{array}$ & $\begin{array}{l}\text { Patients } \\
\text { (no.) }\end{array}$ & $\begin{array}{l}\text { \% with diabetic } \\
\text { complications }\end{array}$ \\
\hline$<5$ & 78 & 4 \\
$5-9$ & 23 & 9 \\
$9-13$ & 35 & 20 \\
$\geqslant 13^{\text {b }}$ & 24 & 50 \\
\hline
\end{tabular}

${ }^{a}$ Retinopathy, nephropathy, necrobiosis lipoidica diabeticorum.

b Median, 23 years; range, 13 to 36 years.

and of diabetes and the mean duration of diabetes were not significantly different in the patients with and without diabetic retinopathy or nephropathy. The diabetes preceded the pancreatitis in three of the four patients by a mean of 7 years (range, 3 to 13 years) and followed the pancreatitis in one patient by 4 years.

Hyperlipidemia was not a significant feature in those patients in whom lipid determinations were carried out. However, $75 \%$ of the patients with complications were on insulin therapy, indicating a more severe form of diabetes, whereas only $25 \%$ of those without complications were on insulin therapy.

The diabetic microangiopathy seen in the four patients with acute pancreatitis was retinopathy (non-proliferative) in three and retinopathy and nephropathy in one. The one patient with nephropathy had a family history of diabetes, and had the diabetes for 13 years, dating from before the pancreatitis, and was on insulin treatment.

There were 146 patients with chronic pancreatitis and diabetes (Table 5). Fourteen percent (20 patients) with chronic pancreatitis had clinically evident diabetic microangiopathy. Retinopathy and nephropathy occurred in $14 \%$ of the patients with a positive family history and in an equal proportion (13\%) of those with a negative family history. The only statistically significant $(p<0.001)$ difference between patients with microangiopathy and those without microangiopathy was the longer mean duration of diabetes among those with microangiopathy.

The diabetes preceded the pancreatitis in about $30 \%$, by a mean of 7 years (range, 0.3 to 25 years), was simultaneous with pancreatitis in $17 \%$, and followed the pancreatitis in approximately half, by a mean of 8 years (range, 1 to 34 years). Again, significant hyperlipidemia was not present in this group of patients with or without microangiopathy. Insulin treatment was required in $90 \%$ of the patients with microangiopathy and in $56 \%$ of those without microangiopathy.

The complications noted in these 20 patients were as follows: retinopathy in 19 (nonproliferative in 17

Table 4. Summary of Findings in 22 Patients with Acute Pancreatitis

\begin{tabular}{|c|c|c|}
\hline & $\begin{array}{l}\text { With } \\
\text { microangiopathy }\end{array}$ & $\begin{array}{l}\text { Without } \\
\text { microangiopathy }\end{array}$ \\
\hline No. of patients & $\begin{array}{l}4 \\
(4 M)\end{array}$ & $\begin{array}{l}18 \\
(13 \mathrm{M} ; 5 \mathrm{~F})\end{array}$ \\
\hline Pos. family history (no.) & 2 & 6 \\
\hline \multicolumn{3}{|l|}{ Age at onset $(\mathrm{yr})^{\mathrm{b}}$} \\
\hline of pancreatitis & $57(45-74)$ & $50(23-75)$ \\
\hline of diabetes & $52(29-69)$ & $50(23-75)$ \\
\hline Duration of diabetes $(y r)^{b}$ & $8(3-13)$ & $3(0-11)$ \\
\hline \multicolumn{3}{|l|}{ Temporal relationship (no.) } \\
\hline Diabetes first & 3 & 4 \\
\hline Simultaneous & 0 & 7 \\
\hline Pancreatitis first & 1 & 7 \\
\hline Serum cholesterol $(\mathrm{mg} / \mathrm{dl})^{\mathrm{b}}$ & $\begin{array}{l}218(117-317) \\
N=4\end{array}$ & $\begin{array}{l}202(144-276) \\
N=13\end{array}$ \\
\hline Serum triglycerides $(\mathrm{mg} / \mathrm{dl})^{\mathrm{b}}$ & $\begin{array}{l}93(69 ; 117) \\
N=2\end{array}$ & $\begin{array}{l}155(72-288) \\
N=4\end{array}$ \\
\hline \multicolumn{3}{|l|}{ Diabetes treatment (no.) } \\
\hline Diet & 1 & 10 \\
\hline Oral agents & 0 & 3 \\
\hline Insulin & 3 & 5 \\
\hline
\end{tabular}

a Retinopathy and nephropathy or both.

${ }^{b}$ Mean and range. 
Table 5. Summary of Findings in 146 Patients with Chronic Pancreatitis

\begin{tabular}{|c|c|c|}
\hline & $\begin{array}{l}\text { With } \\
\text { microangiopathy }\end{array}$ & $\begin{array}{l}\text { Without } \\
\text { microangiopathy }\end{array}$ \\
\hline No. of patients & $\begin{array}{l}20 \\
(11 \mathrm{M} ; 9 \mathrm{~F})\end{array}$ & $\begin{array}{l}126 \\
(101 \mathrm{M} ; 25 \mathrm{~F})\end{array}$ \\
\hline Pos. family history (no.) & $\begin{array}{l}8(40 \%) \\
(5 \mathrm{M} ; 3 \mathrm{~F})\end{array}$ & $\begin{array}{l}47(37 \%) \\
(35 \mathrm{M} ; 12 \mathrm{~F})\end{array}$ \\
\hline \multicolumn{3}{|l|}{ Age at onset $(y r)^{b}$} \\
\hline of pancreatitis & $46(23-67)$ & $48(6-82)$ \\
\hline of diabetes & $43(6-65)$ & $51(24-82)$ \\
\hline Duration of diabetes $(\mathrm{yr})^{\mathrm{b}}$ & $15(3-36)$ & $6(0-34)$ \\
\hline \multicolumn{3}{|l|}{ Temporal relationship (no.) } \\
\hline Diabetes first & 11 & 32 \\
\hline Simultaneous & 2 & 23 \\
\hline Pancreatitis first & 7 & 71 \\
\hline Serum cholesterol $(\mathrm{mg} / \mathrm{dl})^{\mathrm{b}}$ & $\begin{array}{l}201(124-360) \\
N=15\end{array}$ & $\begin{array}{l}215(122-358) \\
N=68\end{array}$ \\
\hline Serum triglycerides $(\mathrm{mg} / \mathrm{dl})^{\mathrm{b}}$ & $\begin{array}{l}89(66-135) \\
N=3\end{array}$ & $\begin{array}{l}126(49-208) \\
N=12\end{array}$ \\
\hline \multicolumn{3}{|l|}{ Diabetes treatment (no.) } \\
\hline Diet & 2 & 39 \\
\hline Oral agents & 0 & 17 \\
\hline Insulin & 18 & 70 \\
\hline
\end{tabular}

ancludes retinopathy or nephropathy or both, and necrobiosis lipoidica diabeticorum.

bean and range.

and proliferative in 2), nephropathy in 2 (both of these patients had retinopathy), and necrobiosis lipoidica diabeticorum in 1.

Of the 19 patients with retinopathy, 10 had developed diabetes prior to the diagnosis of pancreatitis; the mean duration of the diabetes was 15 years (range, 3 to 36 years). Seventeen of these 19 patients required insulin therapy, and mean lipid values were within the normal range in the patients in whom the determinations were performed. Eight had a family history of diabetes.

The two patients with nephropathy had had their diabetes for 14 and 21 years and the diabetes preceded the pancreatitis by 5 and 17 years, respectively. One patient had a family history of diabetes, and only one of the patients was on insulin therapy.

The one patient with necrobiosis lipoidica diabeticorum did not have a family history of diabetes, but the diabetes preceded the pancreatitis.

Table 6 shows the occurrence of retinopathy and nephropathy in pancreatitis associated with chronic alcoholism and cholelithiasis. In those patients with diabetes mellitus for 10 or more years, the frequency of microangiopathy was least in patients with pancreatitis and chronic alcoholism.
Quantitative stool studies for fat excretion were carried out in 72 patients with chronic pancreatitis. The mean fat excretion in these patients was $33 \mathrm{~g} / 24 \mathrm{~h}$ (range, $8-212 \mathrm{~g} / 24 \mathrm{~h}$ ). The degree of steatorrhea did not appear to have a favorable influence on the occurrence of microangiopathy (Table 7).

In the patients with acute pancreatitis without evidence of malabsorption, $18 \%$ had clinically evident diabetic microangiopathy, compared to $14 \%$ of the patients with chronic pancreatitis, suggesting that malabsorption may exert a protective effect on the development of the microangiopathy in pancreatitic diabetes. However, the degree of malabsorption or the amount of steatorrhea showed no demonstrable beneficial effect on this complication.

The less specific lesions of diabetes - such as macroangiopathy (coronary heart disease, peripheral vascular disease, and cerebrovascular disease) and neuropathy (distal polyneuropathy and mononeuropathy) - occurred alone or in association with each other in $27 \%$, or in conjunction with microangiopathy in $11 \%$, of these patients with pancreatitic diabetes.

Postmortem examination, performed on seven patients, disclosed no evidence of nodular or diffuse glomerulosclerosis. However, the mean duration of 
Table 6. Chronic Diabetic Complications and Associated Disorders of Pancreatitis in 168 Patients

\begin{tabular}{|c|c|c|c|c|c|}
\hline & $\begin{array}{l}\text { Chronic } \\
\text { alcoholism }\end{array}$ & Cholelithiasis & $\begin{array}{l}\text { Chronic } \\
\text { alcoholism \& } \\
\text { cholelithiasis }\end{array}$ & $\begin{array}{l}\text { Familial } \\
\text { pancreatitis }\end{array}$ & None $^{a}$ \\
\hline No. of patients & 52 & 37 & 5 & 2 & 72 \\
\hline Family history of diabetes (no.) & 22 & 13 & 2 & 0 & 31 \\
\hline \multicolumn{6}{|l|}{ Duration of diabetes (yr) } \\
\hline Mean & 5 & 7 & 9 & $\ldots$ & 8 \\
\hline Range & $0-34$ & $0-36$ & $5-20$ & $0.5 ; 1$ & $0-23$ \\
\hline \multicolumn{6}{|l|}{ Complications } \\
\hline Retinopathy & 3 & $4^{b}$ & 3 & 0 & $12^{\mathrm{c}}$ \\
\hline Retinopathy \& nephropathy & 0 & $1^{b}$ & 0 & 0 & $2^{\mathrm{b}}$ \\
\hline Necrobiosis lipoidica diabeticorum & 0 & $1^{\mathrm{b}}$ & 0 & 0 & 0 \\
\hline Diabetes for $10 \mathrm{yr}$ or more & 7 & 10 & 2 & 0 & 32 \\
\hline Retinopathy & 1 & $3^{b}$ & 1 & 0 & 9 \\
\hline Retinopathy \& nephropathy & $\dot{0}$ & $1^{\mathrm{b}}$ & 0 & 0 & 2 \\
\hline Necrobiosis lipoidica diabeticorum & 0 & $1^{b}$ & 0 & 0 & 0 \\
\hline
\end{tabular}

a No associated disorders: "idiopathic."

b Diabetes preceded pancreatitis.

${ }^{c}$ Diabetes preceded pancreatitis in 8 patients; 5 patients had a family history of diabetes.

Table 7. Quantitative Stool Fat Excretion and Occurence of Microangiopathy in 72 Patients with Chronic Pancreatitis

\begin{tabular}{lcc}
$\begin{array}{l}\text { Stool fat } \\
(\mathrm{g} / 24 \mathrm{~h})\end{array}$ & No. & $\begin{array}{l}\text { \% with } \\
\text { microangiopathy }\end{array}$ \\
\hline $8-20$ & 34 & 9 \\
$>20$ & 38 & 13 \\
\hline
\end{tabular}

a Retinopathy or nephropathy or both, and necrobiosis lipoidica diabeticorum.

diabetes in this group was 6 years (range, 0 to 19 years). One of these patients (with the longest duration of diabetes) had nonproliferative retinopathy clinically. Two of these patients had acute pancreatitis. The diabetes preceded the pancreatitis in three of the patients, was simultaneous with the pancreatitis in two, and followed it in two.

\section{Discussion}

The highest incidence of clinically evident diabetic microangiopathy (retinopathy and nephropathy) occurred in those patients whose diabetes preceded the onset of pancreatitis and who had a family history of diabetes. These patients also characteristically were on insulin treatment. Macroangiopathy (coronary heart disease, peripheral vascular disease, and cere- brovascular disease) and neuropathy (distal polyneuropathy and mononeuropathy) occurred in the patients with pancreatitic diabetes, but were less specific complications of the diabetes. Whether patients with pancreatitic diabetes and microangiopathy represent "primary" (genetic) diabetes mellitus, regardless of the presence of a family history of diabetes, is a moot point. The presence of retinopathy in patients with pancreatitic diabetes with a negative family history of diabetes suggests that indeed these patients may be "primary" diabetics whose underlying genetic trait for diabetes has been unmasked by the pancreatitis. Perhaps the latent genetic diabetic is more susceptible to pancreatitis.

The frequency of diabetic microangiopathy is significantly correlated with the duration of the diabetes and may be influenced by the presence of malabsorption, but the diagnosis of diabetes prior to the diagnosis of pancreatitis, the need for insulin therapy for control of the diabetes, and a family history of diabetes appear to be more significant factors in the increased frequency of diabetic microangiopathy. Nutritional factors may influence the development of microangiopathy $[3,11,12]$, but the degree of steatorrhea in the patients with chronic pancreatitis in this study did not suggest a protective effect against the development of microangiopathy.

Whether or not the treatment of the diabetes plays any role in the manifestations of the diabetic microangiopathy cannot be ascertained from these data. The treatment of the diabetes probably does not con- 
tribute to the manifestations, but rather reflects the severity of the diabetes.

There is no demonstrable significant correlation of diabetic microangiopathy with the age at onset of either condition or with the duration of the pancreatitis. Diabetic microangiopathy appears to occur with almost equal frequency in the diabetics with acute or with chronic pancreatitis; it occurs least frequently in pancreatitis associated with chronic alcoholism.

Thus, primary and secondary diabetes mellitus cannot be differentiated with certainty on the basis of whether or not diabetic microangiopathy is present. The presence of diabetic microangiopathy (particularly proliferative retinopathy or glomerulosclerosis) in a patient with pancreatitis and diabetes tends to indicate primary diabetes, but pancreatitic diabetes with or without microangiopathy may be part of the heterogeneous spectrum of "primary" diabetes in which the underlying genetic diabetes becomes manifest when pancreatitis develops.

\section{References}

1. College of General Practitioners: Glucose tolerance and glycosuria in the general population: report of a working party. Brit. med. J. 1963 II, 655-659

2. Comfort, M.W., Gambill, E.E., Baggenstoss, A.H.: Chronic relapsing pancreatitis: a study of twenty nine cases without associated disease of the biliary or gastrointestinal tract. Gastroenterology 6, 239-285, 376-408 (1946)

3. Creutzfeldt, W., Perings, E.: Is the infrequency of vascular complications in human secondary diabetes related to nutritional factors? Acta diabet. lat. (Suppl) 1, 432-445 (1972)
4. Deckert, T.: Late diabetic manifestations in "pancreatogenic" diabetes mellitus. Acta med. scand. 168, 439-446 (1960)

5. Duncan, L.J.P., MacFarlane, A., Robson, J.S.: Diabetic retinopathy and nephropathy in pancreatic diabetes. Lancet $1958 \mathrm{I}, 822-826$

6. Joffe, B.I., Krut, L., Bank, S., Marks, I. N., Keller, P.: Serum lipid levels in diabetes secondary to chronic pancreatitis. Metabolism 19, 87-90 (1970)

7. Johansen, K., Ørnsholt, J.: Frequency of diabetes after acute pancreatitis. Metabolism 21, 291-296 (1972)

8. King, S.E.: The syndrome of chronic relapsing pancreatitis: the frequency of insular deficiency (pancreatic diabetes) in the fibrocalcific state. Med. Clin. N. Amer. 33, 883-897 (1949)

9. Marks, I.N., Bank, S.: The aetiology, clinical features and diagnosis of pancreatitis in the South Western Cape: a review of 243 cases. S. Afr. med. J. 37, 1039-1053 (1963)

10. O'Sullivan, J.N., Nobrega, F.T., Morlock, C.G., Brown, A.L., Jr., Bartholomew, L.G.: Acute and chronic pancreatitis in Rochester, Minnesota, 1940 to 1969. Gastroenterology 62, 373-379 (1972)

11. Osuntokun, B. O.: Diabetic retinopathy in Nigerians: a study of 758 patients. Br. J. Ophthal. 53, 652-663 (1969)

12. Osuntokun, B.O.: The neurology of non-alcoholic pancreatic diabetes mellitus in Nigerians. J. neurol. Sci. 11, 17-43 (1970)

13. Sarles, H.: Proposal adopted unanimously by the participants of the Symposium. Bibl. gastroent. (Basel) 7, 7-8 (1965)

14. Schumacker, H.B., Jr.: Acute pancreatitis and diabetes. Ann. Surg. 112, 177-200 (1940)

15. Sevel, D., Bristow, J.H., Bank, S., Marks, I., Jackson, P.: Diabetic retinopathy in chronic pancreatitis. Albrecht v. Graefes Arch. Ophthal. 86, 245-250 (1971)

16. Sprague, R.G.: Diabetes mellitus associated with chronic relapsing pancreatitis. Proc. Staff Meet. Mayo Clin. 22, $553-558$ (1947)

Dr. P. J. Palumbo

Mayo Clinic

200 First Street SW

Rochester, MN 55901

USA 